\title{
EXERGY FLOWS IN INDUSTRIAL PROCESSES ${ }^{\dagger}$
}

\author{
GÖRAN WALL \\ Physical Resource Theory Group, Chalmers University of Technology and University of Göteborg, \\ SE-412 96 Göteborg, Sweden
}

(Recieved 17 December 1986)

\begin{abstract}
The concept of exergy is defined and applied to industrial processes. We discuss system boundaries and problem definition. The exergy flows and losses for a pulp and paper mill and a steel plant and rolling mill are presented and the exergy losses are determined. The aim is to show the simplicity and value of using the concept of exergy when analyzing industrial processes and to develop conventions and standards within the field. Large losses revealed in an exergy treatment of a process should be seen as a challenge to achieve technical improvements, not as an insurmountable obstacle.
\end{abstract}

\section{INTRODUCTION}

The concept of exergy is coming into increased international use. Nonetheless, the concept of exergy is uncommon in descriptions of industrial processes. This is unfortunate, particularly since the concept of exergy will be used routinely in process analysis in the near future. The concept is both readily understood and easy to apply. This study is based on earlier work. ${ }^{1}$

The main objective is to show the applicability of exergy for studies of industrial processes. The concept of exergy provides an estimate of the minimum theoretical resource requirement (requirement for energy and material) of a process. This, in turn, provides information on the maximum savings that can be achieved by making use of new technology and new processes. New technology and new processes do not come about by themselves. By providing a deeper insight, the exergy concept provides a better foundation for improvement and for calculating expected savings.

Another important goal is to establish standards in order to facilitate applications in industry and in other planning processes such as energy management.

\section{DEFINING THE CONCEPT}

Energy is often defined as work or the ability to perform work. This is wrong. Energy should instead be defined as motion or the ability to produce motion. This is certainly a less specific but a more correct definition. Energy can be defined as that which is indestructible or that which is always conserved during every closed process. Energy is thus most often an all too hazy concept.

In 1824, Carnot published a relation between heat and work, which later resulted in formulation of the second law of thermodynamics. ${ }^{2}$ Gibbs was first and expressed the general relation for work as early as $1873 .{ }^{3}$ Not until 1953 did Rant suggest the name exergy. ${ }^{4}$ A general definition was given by Baehr in $1965 .^{5}$ These four works constitute an adequate definition of the exergy concept, thus establishing a foundation.

In science and technology one has used, for a long time, thermodynamic potentials similar to exergy but more limited in scope. The Gibbs and Helmholz free energies and enthalpy may be viewed as special cases of exergy. 6,7

We may express the energy and exergy concepts in the following simple terms: (1) energy is motion or ability to produce motion and (2) exergy is work or ability to produce work. The laws of thermodynamics may be formulated accordingly: (1) energy is always conserved in a process (1st law) and (2) exergy is always conserved in a reversible process, but is always consumed in an irreversible process (2nd law, the law of exergy).

'The author's thesis which includes all computer programs together with other papers ${ }^{1,7,14}$ and a bibliography of more than 1400 references on exergy is available from Internet at http://www.exergy.se. 
The exergy $E$ of a system may be written as ${ }^{7}$

$$
E=S\left(T-T_{o}\right)-V\left(p-p_{o}\right)+\sum_{i} n_{i}\left(\mu_{i}-\mu_{i o}\right)
$$

where the extensive parameters are entropy $S$, volume $V$ and number of moles of substance $i n_{i}$, and the intensive parameters are temperature $T$, pressure $p$, and chemical potential of substance $i \mu_{i}$ for the system; the subscript $o$ describes the state when thermodynamic equilibrium with the reference environment is established. We clearly see that exergy approaches zero as the system approaches equilibrium with the environment. We also see that exergy here is expressed as the sum of terms for differences in temperature, pressure and chemical potential. The effects of electricity, magnetism, gravity, radiation, etc. can also be added to this expression.

Analogously, the exergy of a flow can be written as

$$
E=H-H_{o}-T_{o}\left(S-S_{o}\right)-\sum_{i} \mu_{i o}\left(n_{i}-n_{i o}\right),
$$

where $H$ is the enthalpy, with the result that the exergy of a steam flow, for example, is calculated from the steam tables.

For mixtures of substances, the calculation of exergy content is somewhat more complicated. The enthalpy can be calculated as the sum of the enthalphies of its substances. The entropy of a mixture, on the other hand, is determined by its nature. An ideal mixture is one where the elements are completely intermixed, i.e. two mixed gases or a drop of ink dissolved in water. The entropy of such mixtures is

$$
S=\sum_{i} x_{i} s_{i}-R \sum_{i} x_{i} \ln x_{i}
$$

where $x_{i}$ is the molar ratio of substance $i, s_{i}$ its entropy, and $R$ the gas constant.

There is no general theory or unequivocal concept for non-ideal mixtures, which is a serious problem in view of the significance of these mixtures. Examples of non- ideal mixtures are alloys, suspensions and emulsions. It has been assumed here that the entropy of such mixtures are the sum of the entropies of the mixed substances, i.e. the last term which gives the entropy of the actual mixing process in Eq. (3) is excluded.

Data on thermal capacities are easily available for pure elements and for certain chemical compounds such as oxides. ${ }^{8}$ The thermal capacity of a mixture has been assumed to be the sum of the values of the substances in relation to their proportion. However, the result is that the mixtures where new phases appear are attributed incorrect values for thermal capacity. However, the size of this error is considered negligible in relation to errors in other data such as quantities and temperatures. Standard states are based on definitions by Szargut. ${ }^{9}$

The study does not include indirect resource costs, such as the energy and materials necessary for manufacturing fixed capital, i.e. machines. The term energy/exergy analysis should be reserved for such studies.

\section{DEFINING THE PROBLEM}

The following example illustrate the importance of a clear problem definition. ${ }^{10}$ Today, when we set about to estimate the energy requirement for cutting a log of lumber into boards, we start out by assuming that the lumber will be sawn. When the price of fuel goes up, we begin by examining whether the process can be improved by selecting a more efficient motor to drive the saw-blade. We conclude that electric motors are usually $90 \%$ efficient and that it is thus not possible to achieve more than a $10 \%$ improvement. But in scientific terms, cutting results in two surfaces of a section which are separated so that the forces of attraction are negligible, i.e. a distance of several atom diameters. If one considers that wood has an ultimate strength of $10^{4} \mathrm{~N} / \mathrm{cm}^{2}$ and that the distance required to separate the surfaces is $3 \times 10^{-9} \mathrm{~m}$ (10 times the diameter of a water molecule), it takes 
less than $0.3 \mathrm{~J}$ to cut a $\log 5 \mathrm{~m}$ long and $20 \mathrm{~cm}$ in diameter. Thus $1 \mathrm{kWhr}$ should suffice to cut 10 millions logs. However, a saw not only creates two new surfaces, but also the surface around each sawdust. Consequently, in the best of cases, a saw with a $1 \mathrm{~kW}$ motor can cut 300 logs of lumber per hour, i.e. 30 logs per $\mathrm{kWhr}$. Hence, it is not true that we can reduce the energy requirement by a maximum of $10 \%$. We can reduce the requirement by more than $10^{5}$ if we find better methods than cutting.

This example is not selected to diminish existing technology, but to put it in a scientific perspective. This is the only way we can perceive the enormous potential of existing technology. We must learn to view the shortcomings of current-day technology as a challenge for improvement, not as an insurmountable obstacle.

The following two sections describe a number of subprocesses in the pulp and paper and steel industry. In those cases where the descriptions are based on earlier energy studies which at times lacked sufficient data for making exergy calculations, estimates have been made. Certain data have been changed when they were shown to be obviously wrong during the exergy calculations. In order to simplify the description, the minor flows were neglected. Efficiency, defined as utilized outflow divided by utilized flows, is also given. Similar studies have also been made by others. ${ }^{11,12}$

\section{A PULP AND PAPER MILL}

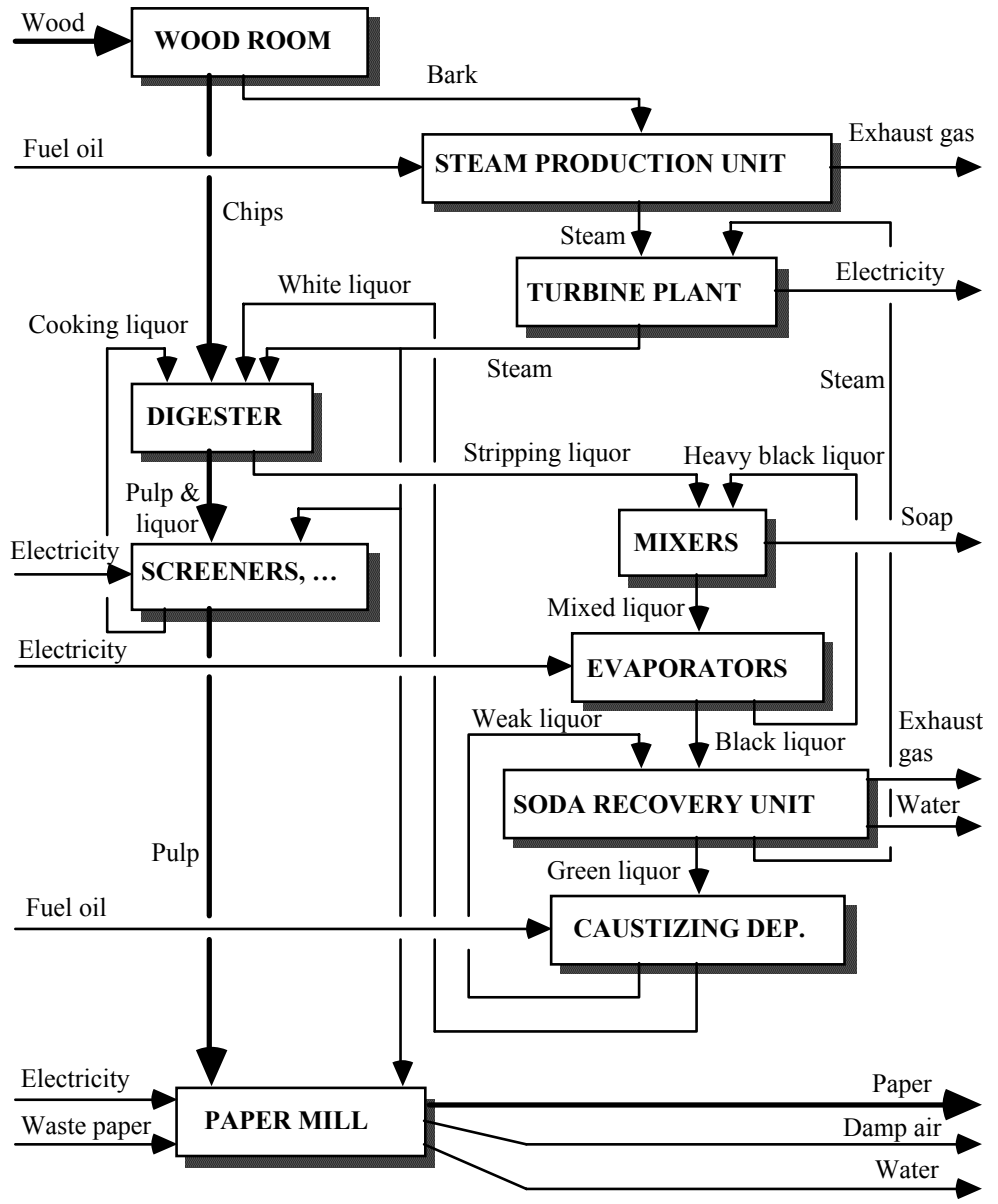

Fig. 1. A pulp and paper mill.

The data used are based on an energy study ${ }^{13}$ of SCA-Nordliner in Munksund, Sweden. In 1979, the mill produced 265,000 tons of unbleached kraft liner, which is used mostly as raw material for corrugated fiberboard, from 210,000 tons of unbleached sulphate pulp and 55,000 tons of recycled waste paper. The plant, which consists of the sulphate pulp factory and of the paper mill, is 
schematically illustrated in Fig. 1. The process may be briefly described as follows: (1) The wood is separated from the bark. The bark is combusted in a steam production unit and the wood chipped. (2) The chips are cooked with white liquor at high pressure in the continuous digester. (3) The pulp and liquor are removed from the bottom of the digester by a blower mixer, to be screened, washed and refined. (4) The pulp is then dried in the paper mill by dewatering, pressing and through evaporation.

The exergy flows of every subprocess per ton of produced paper (tp) are estimated. Note that the paper mill supplies fiber via waste paper which accounts for the fact that the real production of pulp in a pulp factory is equivalent to a production of about 0.78 tons of paper. (In order to obtain values in ton per ton of pulp, this should be multiplied by a factor of 1.22.) The yield of the process, given as quantity of dry wood (fiber) in the paper, is $57 \%$.

Table 1 gives the assumed chemical composition of the flows in the process. Figure 2 shows the exergy flows in the entire process. The most exergy-intensive processes are readily distinguishable. It is also interesting that large quantities of exergy in the form of liquor and black liquor (or concentrated waste liquor) circulate through the process. The circuit of the processing chemicals in the stripping liquor, mixed (or semi thickened) liquor, black liquor, green liquor and white liquor can also be readily discerned. A description of each subprocess is given below.

\section{Wood room}

The incoming wood is separated from ice and snow with hot water prior to debarking in the barking drum. The bark is pressed in order to reduce its water content and thus upgrade its fuel value.

\section{Continuous digester}

The digester is continuous and of the KAMYR type. The wood chips and white liquor are continuously fed into the upper part of the digester while the pulp is removed from the lower part (of the digester) using liquor (pulp and liquor: 10.64 tons/tp). The processing chemicals, which are removed with the stripping liquor, are recovered by means of the white liquor.

\section{Screening, washing and refining}

The pulp is pulverized, refined and separated from the liquor.

\section{Mixers and heat exchangers}

The liquor leaving the digester is thickened by being mixed with the black liquor to enable it to be processed in the evaporator and soap is skimmed off. Mixing takes place in stages which, at the same time, yield valuable steam.

\section{Evaporator plant}

The mixed liquor is evaporated to about $60 \%$ of dry content (black liquor) by being steamed in order to be more efficiently combusted later in the soda recovery unit. In order to keep steam

Table 1. Assumed chemical composition of substances in the pulp and paper mill.

\begin{tabular}{l|c|r|r|r|r|c|c}
\hline Substance & $\mathrm{H}$ & \multicolumn{1}{|c|}{$\mathrm{H}_{2} \mathrm{O}$} & $\mathrm{C}$ & $\mathrm{O}$ & $\mathrm{Na}_{2} \mathrm{CO}_{3}$ & $\mathrm{NaOH}$ & $\mathrm{Na}_{2} \mathrm{~S}$ \\
\hline Stripping liquor & 0.6 & 85.8 & 4.7 & 3.9 & 0.9 & 2.5 & 1.6 \\
Bark (0.4\% N) & 2.4 & 60.0 & 20.0 & 17.2 & & & \\
Mixed liquor & 0.9 & 76.2 & 7.4 & 6.4 & 1.7 & 4.5 & 2.8 \\
Green liquor & & 80.8 & & & 14.0 & & 5.2 \\
Liquor & 0.7 & 88.7 & 6.9 & 3.3 & 0.1 & 0.2 & 0.1 \\
Pulp & 0.8 & 87.1 & 6.3 & 5.8 & & & \\
Pulp \& liquor & 1.4 & 78.0 & 12.4 & 7.6 & 0.1 & 0.3 & 0.2 \\
Paper/kraft liner & 5.8 & 7.6 & 45.0 & 41.6 & & & \\
Waste paper & 4.6 & 26.4 & 35.9 & 33.1 & & & \\
Waste liquor & 0.9 & 77.2 & 7.5 & 6.2 & 1.5 & 4.1 & 2.6 \\
Weak liquor & & 95.9 & & & 3.0 & & 1.1 \\
Soap & 4.7 & 27.6 & 46.9 & 20.9 & & & \\
Black liquor & 3.3 & 39.6 & 18.8 & 16.3 & 4.2 & 11.5 & 7.2 \\
Wood/chips & 3.1 & 50.0 & 25.0 & 21.9 & & & \\
White liquor & & 83.2 & & & 3.1 & 8.4 & 5.3 \\
\hline
\end{tabular}




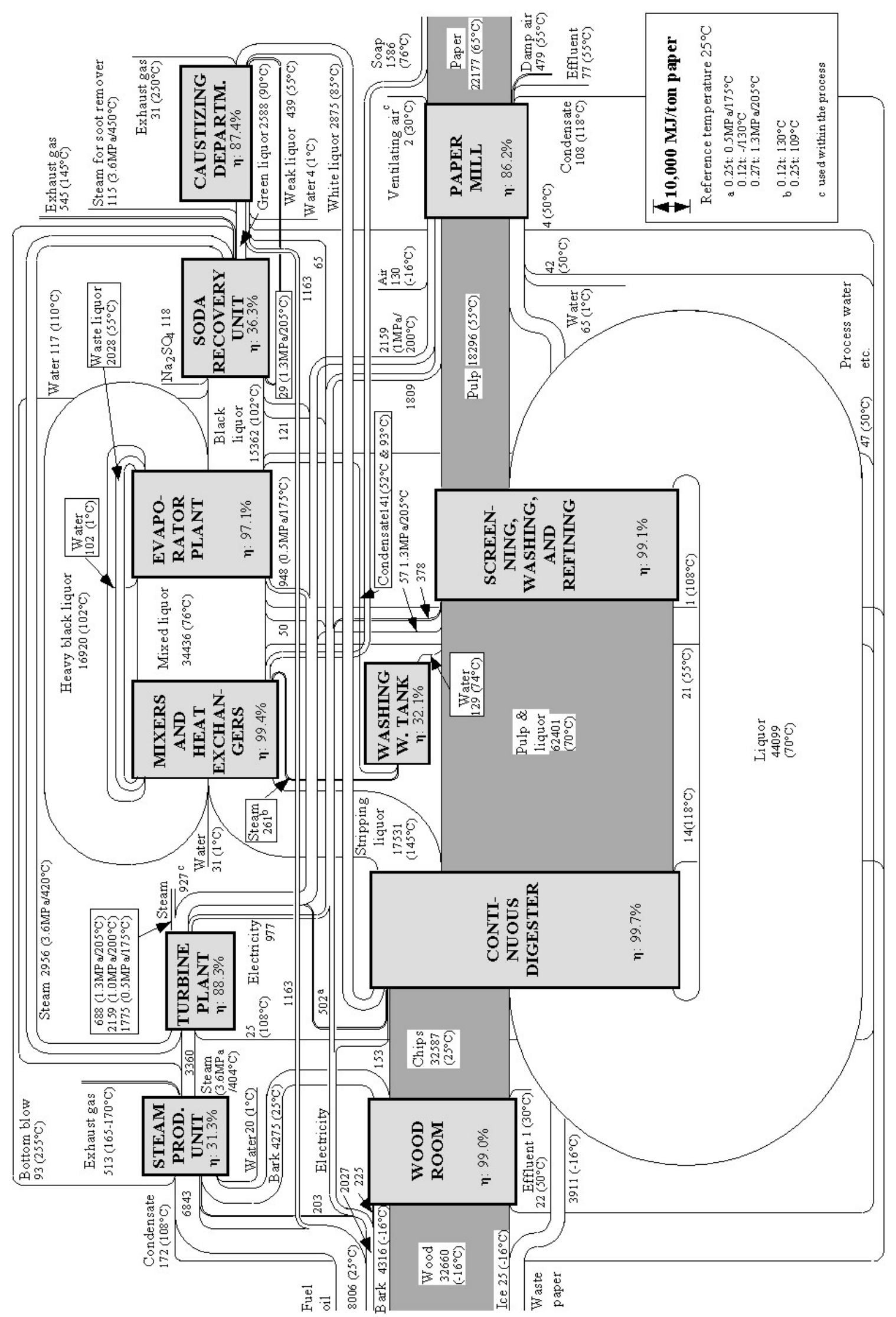

Fig. 2. Exergy flow through a pulp and paper mill for a Swedish kraft liner mill (SCA-Munksund) during January 1979. 
consumption to a minimum, this process takes place in several steps at successively lower temperatures and pressures.

\section{Soda recovery unit}

The organic substances in the black liquor released from the wood in the continuous digester are combusted in the soda recovery unit. Small quantities of chemicals such as sodium sulphate (about $30 \mathrm{~kg} / \mathrm{tp}$ ) are added to the black liquor to replace the chemicals that were lost in the pulping process. The non-combusted substances in the concentrated liquor, are recovered mainly as green liquor. In the causticizing department this is converted to the white liquor. The soda recovery unit is essentially a chemical reactor for recovering the processing chemicals present in the concentrated liquor. Energy efficiency is considered only once the safety and environmental requirements have been fulfilled. This explains the unit's low exergy efficiency, which is a mere $36.3 \%$.

\section{Steam production unit}

The production of steam from the combustion of the black liquor in the soda recovery unit does not suffice to meet the steam requirement of the mill, which is why a special steam production unit is installed. The bark and fuel oil are combusted and converted to steam at a very low exergy efficiency.

\section{Turbine}

The steam produced in the soda recovery unit and the steam production unit has considerably higher pressure and temperature than is necessary for the process. The steam can therefore by utilized in a back pressure turbine to generate electricity.

\section{Lime sludge reburning kiln and causticizing}

In the causticizing department, the green liquor, which contains soda and sodium sulphide, is converted, causticized, to the white liquor. Sodium sulphide is used for pulp processing while the soda must be converted to sodium hydroxide before it can work effectively. This is done by adding lime to the green liquor.

$$
\begin{gathered}
\mathrm{Na}_{2} \mathrm{CO}_{3}+\mathrm{CaO}+\mathrm{H}_{2} \mathrm{O} \rightarrow 2 \mathrm{NaOH}+\mathrm{CaCO}_{3} \\
(\text { soda }+ \text { lime }+ \text { water } \rightarrow \text { sodium hydroxide }+ \text { calcium carbonate })
\end{gathered}
$$

\section{Paper mill}

The paper mill manufactures kraft liner which is built up of two layers. The bottom layer is made up of relatively roughly ground pulp, so-called base pulp (base stock), while the upper layer, which is thinner, is called top stock.

Nearly $100 \%$ of the supplied steam is used to dry the pulp to paper. The moist air thus obtained as a by-product is utilized to a minor extent to preheat the ventilation air. The supplied waste paper represents a fiber addition of about 0.2 tons/tp.

In a final product that contains about 0.93 tons of fiber, the extra fiber from the waste paper constitutes about $22 \%$. If this extra fiber is removed from the process, the supplied raw material must correspondingly increase, that is, be multiplied by a factor of 1.28 to reach the same quantity of produced paper, i.e. 1 ton.

\section{The total process}

Table 2 is a compilation of every subprocess and gives the quantitative and percentual energy and exergy losses relative to the entire mill. The total losses also include the unutilized outflows. Of the direct energy losses of the mill, the predominant losses are incurred in the soda recovery unit which accounts for more than half of the energy losses (columns 1 and 2). Considerable losses are also incurred during screening, steam production and in the paper mill. If we also include the unutilized process flows (columns 3 and 4), the losses incurred in the soda recovery unit appear to be somewhat less. The steam production unit and the paper mill, which yielded considerable energy losses in the form of moist air and hot water now also play an important role. 
Table 2. Energy and exergy losses in the pulp and paper mill.

\begin{tabular}{l|r|r|r|r|r|r|r|r}
\hline & \multicolumn{4}{|c|}{ Energy losses } & \multicolumn{4}{c}{ Exergy losses } \\
\hline Process: & Direct & \multicolumn{1}{|c|}{$\%$} & Total & \multicolumn{1}{c}{$\%$} & Direct & $\%$ & Total & $\%$ \\
\hline Wood room & 65 & 0.8 & 194 & 1.0 & 385 & 1.6 & 386 & 1.5 \\
Continuous digester & 169 & 2.0 & 169 & 0.8 & 270 & 1.1 & 270 & 1.0 \\
Screening, etc. & 1087 & 12.7 & 1087 & 5.4 & 570 & 2.3 & 570 & 2.1 \\
Mixers, etc. & 42 & 0.5 & 42 & 0.2 & 206 & 0.8 & 206 & 0.8 \\
Evaporation & 840 & 9.8 & 840 & 4.2 & 1039 & 4.2 & 1039 & 3.9 \\
Soda recovery unit & 4485 & 52.5 & 7228 & 36.2 & 9889 & 39.9 & 10549 & 39.8 \\
Steam production unit & 1271 & 14.9 & 3405 & 17.0 & 7616 & 30.8 & 8129 & 30.6 \\
Turbine plant & 3 & 0.0 & 3 & 0.0 & 742 & 3.0 & 742 & 2.8 \\
Caustizing department & 16 & 0.2 & 132 & 0.7 & 479 & 1.9 & 510 & 1.9 \\
Paper mill & 560 & 6.6 & 6875 & 34.4 & 3569 & 14.4 & 4125 & 15.6 \\
& & & & & & & & \\
\hline Total & 8538 & 100 & 19975 & 100 & 24765 & 100 & 25526 & 100 \\
\hline
\end{tabular}

From the direct exergy losses (columns 5 and 6) we also conclude that the soda recovery unit, the steam production unit, and the paper mill are the least efficient conversion processes. However, we see that the steam production unit now appears as a considerably larger source of loss than previously. This picture holds even when we compare the values in the last two columns which include the exergy losses in the unutilized process flows. From the column showing the direct exergy losses, we also see that exergy losses are almost equally distributed among the other processes. We also see a dramatic difference between the sum of the direct and total energy and exergy losses. In the case of energy, the unutilized outflows, i.e. the difference between the total and the direct losses, constitute $57 \%$ of the total losses but in the case of exergy, only $7 \%$. The unutilized outflows are, essentially; a much smaller resource than energy calculation reveals. This constitutes the largest difference between an energy and an exergy treatment.

The losses in the paper mill can be partly justified by the considerable demands of the readymade product. This is also the final subprocess, which indicates that the all to large direct demands on the limiting of energy and exergy losses may result in an increased number of rejects which may result in even higher total losses for the entire factory. The immediate efforts to increase exergy efficiency should therefore be directed at the soda recovery unit and the steam production unit.

In Table 3, we see that the exergy losses are predominantly exhaust gases and damp air which, of course, are strongly linked to the soda recovery unit and steam plants. The temperature of the exhaust gases varies between $145^{\circ} \mathrm{C}$ and $170^{\circ} \mathrm{C}$. This makes the exhaust gases interesting from the point of view of electricity production. However, of immediate interest is the preheating of air and fuel. The temperatures of the damp air and water are so low that they can only be applicable for space heating purposes or possibly as a heat source in a heat pump system.

Table 3. Unutilized outflows.

\begin{tabular}{l|r|c|r|c}
\hline Unutilized outflows: & Energy & $\%$ & Exergy & $\%$ \\
\hline Damp air & 4680 & 40.9 & 479 & 27.2 \\
Flue gas and soot blowing & 4993 & 43.7 & 1204 & 68.4 \\
Water $\left(30-55^{\circ} \mathrm{C}\right)$ & 1764 & 15.4 & 78 & 4.4 \\
\hline Total & 11437 & 100 & 1761 & 100 \\
\hline
\end{tabular}

Thus, an exergy calculation for the mill reveals that the soda recovery unit and steam production unit ought to be made more efficient. That this is possible to accomplish can also be seen by looking at the combustion efficiencies of these two, which are a mere $27 \%$ and $31 \%$, respectively. The disparity between the exergy price and capital costs, however, indicates that the calculation method ought to be taken further, for example, using thermoeconomic methods. ${ }^{14}$

Let us now treat the entire factory as a process of conversion where investments like wood yield paper and liquid resin, Fig. 2 (the ice is negligible). We see that about $47 \%$ of the incoming exergy remains in the final product. Of the exergy content of the incoming wood, about $56 \%$ remains in the manufactured paper. This value can be compared with the yield, $57 \%$, measured as dry substance. 
For the process as a whole, the result can be a nearly double exergy yield from the wood. At present, it is impossible to say how this can be accomplished. A first step towards more exergyefficient processes would be to channel efforts to improve the mill in accordance with the exergy losses. However, in the short run, research efforts ought to be directed primarily to improve the soda recovery unit. This study is concerned with exergy and does not deal with other aspects such as practical and economic which are also relevant. Other studies are needed to provide additional justification to the proposed measures.

\section{A STEEL PLANT AND A ROLLING MILL}

The data for this study are based on a energy study ${ }^{15}$ of Halmstads Järnverk. The energy calculations in this study differ from those of Fors and Hardell ${ }^{14}$ in terms of the chemical energy in the material that has not been combusted. Moreover, different methods have been used for calculating the heat content which yields values for the exhaust heat, for instance.

The Halmstad steel plant had an annual production capacity of about 280,000 tons of reinforcing steel in 1976. The present study deals with the steel plant and with the rolling mill. The raw material is melted in two electric steel furnaces with a 50 tons capacity each and is then cast in two continuous casting machines with three continuous runs each. The billets are rolled in two rolling mills (mill 5 and 6) to bars and wires of circular crossections of 6 to $32 \mathrm{~mm}$. Figure 3 gives a schematic illustration of the process. The exergy flow per ton of produced reinforcing steel (tr) are estimated for every subprocess.

Figure 4 illustrates the exergy flow in the steel plant and rolling mill. The widths of the illustrated flows are proportional to the exergy content. Total inflow is about $12,700 \mathrm{MJ} / \mathrm{tr}$ and the total outflow of reinforcing steel is about $6800 \mathrm{MJ} / \mathrm{tr}$. The unutilized outflows are equivalent to about $1000 \mathrm{MJ} / \mathrm{tr}$ which yields an exergy efficiency of 54\%. This diagram also provides a good overall picture of the mill's resource flows of electricity, fuel oil, heat and steel.

\section{Electric steel furnaces}

Scrap iron is melted and, in order to obtain the right chemical composition, alloying materials are added. Lime and fire-resistant material as well as graphite from electrodes are consumed. Large quantities of cooling water are used to maintain the furnace at a low and stable temperature. The chemical exergy value of the scrap iron increase from 6.45 to $6.84 \mathrm{MJ} / \mathrm{kg}$ in the readymade steel, which represents a small change in exergy but a very important change in quality.

\section{Continuous casting}

The solidifying steel is cooled with water as it is cast and subsequently cut into suitable lengths to billets. As the steel is cooled, the thermal energy and exergy in the hot billets is lost. The hot billets are placed on a cooling bed, where the temperature drops from about $850^{\circ} \mathrm{C}$ to about $450^{\circ} \mathrm{C}$. Because in the later stages of processing, the steel is handled with magnets, the temperature must be lowered to well below Curie temperature, which is about $770^{\circ} \mathrm{C}$. During the cold season of the year, this heat is used for space heating. From the cooling bed the billets are placed on wagons outside awaiting transport to the rolling mill. As a rule, the temperature drops to somewhere between $100^{\circ} \mathrm{C}$ and the prevailing outdoor temperature before the billets are transported to the rolling mill. This process is illustrated in Fig. 4 as a decrease in the outflow from the continuous casting. 


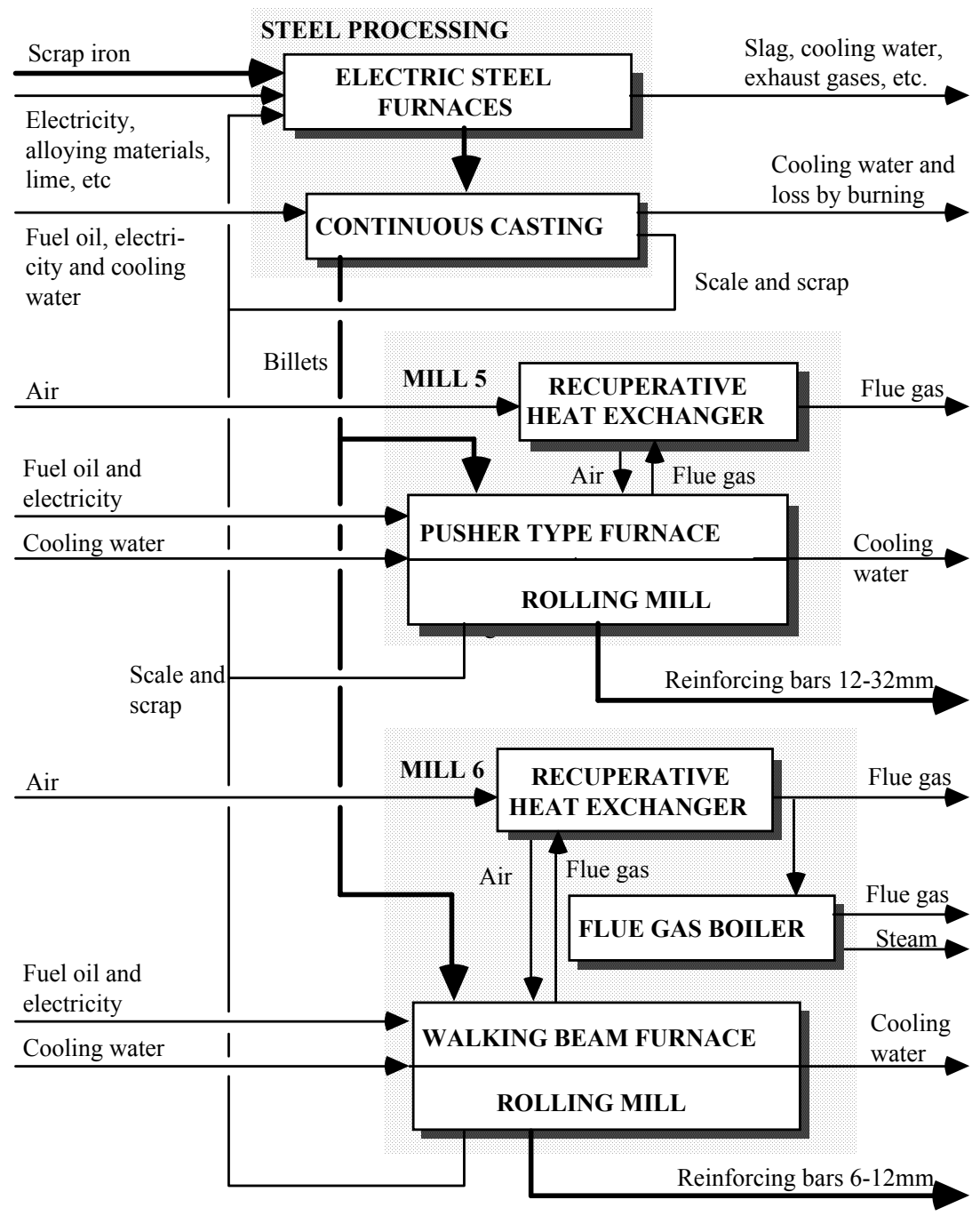

Fig. 3. A steel plant and rolling mill.

\section{Pusher type furnace (mill 5)}

The rolling mill consists of two mills. About two thirds of the billets are rolled in mill 5 . The billets are heated to about $1150^{\circ} \mathrm{C}$ prior to rolling.

\section{Recuperative heat exchanger (mill 5)}

Part of the exhaust heat from the pusher type furnace is used to preheat the combustion air.

\section{Rolling mill (mill 5)}

The hot billets are now rolled to reinforcing bars 12-32 $\mathrm{mm}$ in diameter. Scrap and scale is returned to the electric steel furnaces.

Walking beam furnace, recuperative heat exchanger, and flue gas boiler (mill 6)

Some of the exhaust heat from the walking beam furnace is also used via the recuperative heat exchanger for steam production in a flue gas boiler.

\section{Rolling mill (mill 6)}

Bars and wires of 6-12 $\mathrm{mm}$ are made. 


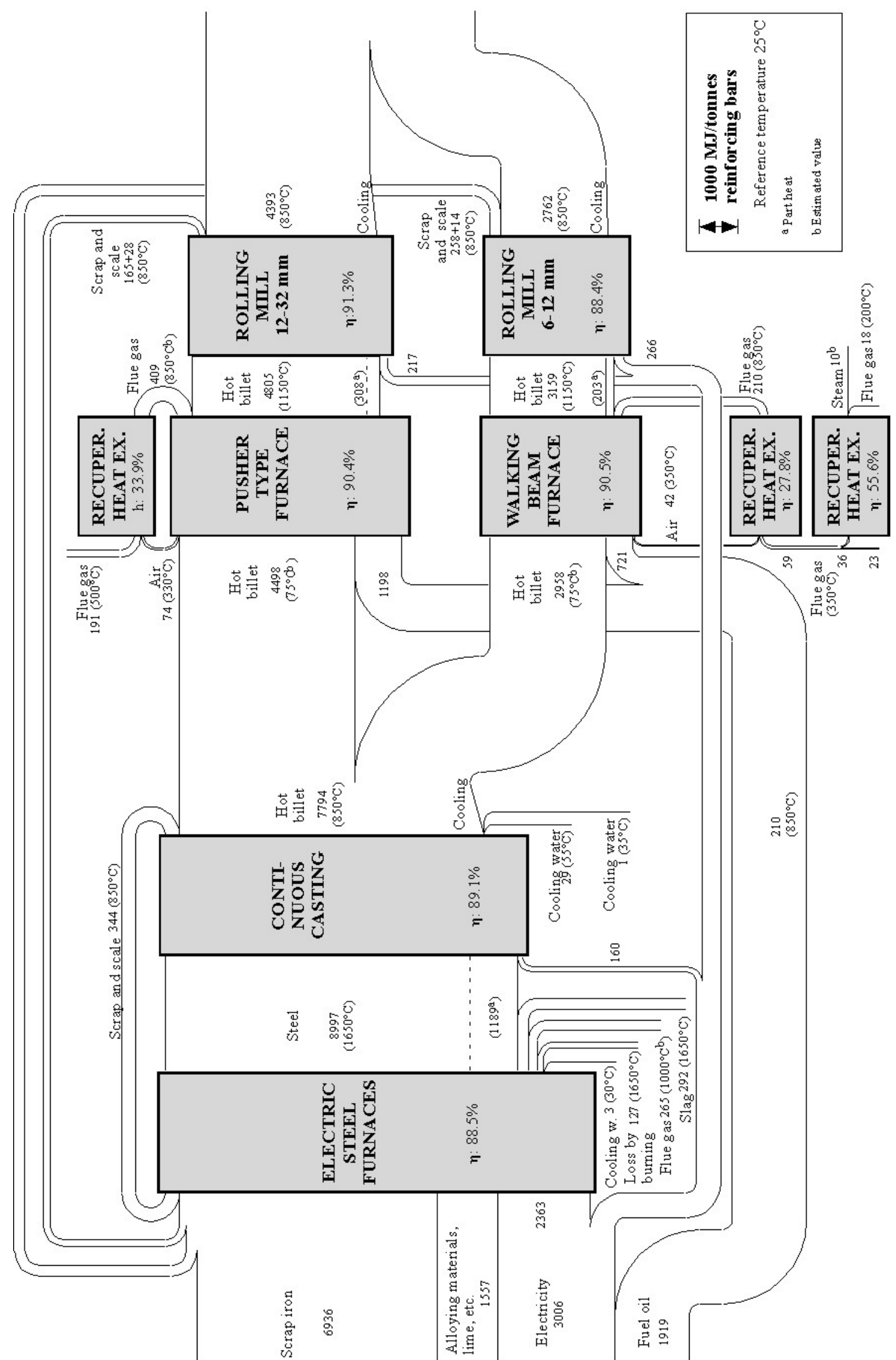

Fig. 4. Exergy flow in a steel plant and rolling mill for (Halmstad Järnverk) 1976. 
Table 4. Energy and exergy losses in the steel plant and rolling mill.

\begin{tabular}{|c|c|c|c|c|c|c|c|c|}
\hline \multirow[b]{2}{*}{ Process: } & \multicolumn{4}{|c|}{ Energy losses } & \multicolumn{4}{|c|}{ Exergy losses } \\
\hline & Direct & $\%$ & Total & $\%$ & Direct & $\%$ & Total & $\%$ \\
\hline Steel process & & & & & & & & \\
\hline Electric steel furnaces & 247 & 7.3 & 1462 & 23.8 & 1172 & 24.2 & 1859 & 32.0 \\
\hline Continuous casting & 517 & 15.3 & 1217 & 19.8 & 989 & 20.4 & 1019 & 17.5 \\
\hline Cooling & 611 & 18.1 & 611 & 10.0 & 353 & 7.3 & 353 & 6.1 \\
\hline Mill 5 & & & & & & & & \\
\hline Pusher type furnace & 175 & 5.2 & 175 & 2.9 & 556 & 11.5 & 556 & 9.6 \\
\hline Recuperative heat ex. & 85 & 2.5 & 585 & 9.5 & 144 & 3.0 & 335 & 5.8 \\
\hline $\begin{array}{l}\text { Rolling mill } \\
\text { Mill } 6\end{array}$ & 481 & 14.3 & 494 & 8.0 & 436 & 9.0 & 446 & 7.7 \\
\hline Walking beam furn. & 131 & 3.9 & 131 & 2.1 & 352 & 7.3 & 352 & 6.1 \\
\hline Recuperative heat ex. & 104 & 3.1 & 179 & 2.9 & 109 & 2.3 & 132 & 2.3 \\
\hline Flue gas boiler & 10 & 0.3 & 84 & 1.4 & 8 & 0.2 & 26 & 0.4 \\
\hline Rolling mill & 420 & 12.5 & 427 & 7.0 & 391 & 8.1 & 397 & 6.8 \\
\hline Mill 5 and 6 & & & & & & & & \\
\hline Cooling water & & & 183 & 3.0 & & & 5 & 0.1 \\
\hline Cooling & 591 & 17.5 & 591 & 9.6 & 329 & 6.8 & 329 & 5.7 \\
\hline Total & 3372 & 100 & 6139 & 100 & 4839 & 100 & 5809 & 100 \\
\hline
\end{tabular}

\section{The total process}

The energy and exergy losses of each subprocess and of the entire plant are shown in Table 4. The total losses consist partly of direct losses in the subprocess itself and during cooling, and partly of unutilized flows. Of the direct energy losses (column 1 and 2), the continuous casting, the first cooling stage, both rolling mills and the final cooling appear as the largest. Together, these account for $2620 \mathrm{MJ} / \operatorname{tr}$ or $77.7 \%$ of the direct energy losses. If we include the unutilized flows (columns 3 and 4), the electric steel furnaces and the continuous casting emerge as the largest sources of loss. More or less the same picture is maintained when we calculate the exergy losses. Moreover, both furnaces contribute considerable exergy losses. These furnaces also consume fuel oil which is used by the mill. It would be possible to utilize the exhaust from all of the furnaces using existing technology so that the exhaust temperature is lowered to below $200^{\circ} \mathrm{C}$ before it leaves the mill. All of the heat losses could also be utilized for electricity production in a low temperature turbine plant.

A simplified compilation of the losses of the mill can be made in order to further point out the differences between an energy and an exergy treatment, see Table 5. In the energy calculation, the losses in the unutilized outflows appear most important beside the direct losses in the process itself. An important difference is that in the exergy calculation, the direct losses constitute the entirely dominant losses. The unutilized outflows, such as waste heat and cooling losses are less important.

We could argue that when the billets are allowed to cool, the total losses should also include the total heating cost later in the process. The total loss during cooling is thus $2257 \mathrm{MJ} / \mathrm{tr}$ (exergy) or about $39 \%$ of the total losses of the mill. This indicates that the casting-rolling process ought to be continuous. However, a completely continuous process is usually impossible to achieve. Instead, various alternatives should be developed, for example, to prevent heat emissions or to utilize the heat for other purposes. Today's steel plant and rolling mills already are attempting to keep the time between the casting and rolling to an absolute minimum. This particular measure ought to be further examined with regard to the large savings, particularly of oil, this could mean.

Table 5. Energy and exergy losses.

\begin{tabular}{l|r|c|r|l}
\hline & Energy losses & $\%$ & Exergy losses & $\%$ \\
\hline Direct losses & 2170 & 35.3 & 4157 & 71.6 \\
Cooling losses & 1202 & 19.6 & 682 & 11.7 \\
Unutilized outflows & 2767 & 45.1 & 970 & 16.7 \\
\hline Total & 6139 & 100 & 5809 & 100 \\
\hline
\end{tabular}




\section{CONCLUSIONS}

The main lesson of the present study is that, of the studied processes, the exergy treatment reveals heating processes as highly inefficient. This is almost always the case for exergy calculations and is due to the fact that the exergy value of heat is often much lower than its energy value, particularly at temperatures close to reference temperature. Thus, processes using higher temperatures, such as melting of iron, are better since the exergy value increases with the temperature above reference temperature. Wastewater at one or two degrees above ambient temperature has, for all practical purposes, no exergy value at all.

At the pulp and paper mill, the soda recovery and the steam production units appeared as the least efficent subprocesses. Within the framework of the earlier mentioned demands of the soda recovery unit, it should be possible to develop better technology for these subprocesses. Perhaps in the future, bacteria and fungi will be able to decompose the wood substances and give us a more efficient technology. An ideal process, which incurs no losses whatsoever, would effect a 50\% reduction in the total use of current resources. Today's pride in the paper and pulp industry over the fact that certain mills do not require external fuel supply such as oil is entirely justified. In the future, when the mill will become a supplier of paper as well as fuel and electricity, there will be even more reason to boast.

The steel industry energy and exergy losses primarly refer to the electric steel furnaces and continuous casting. Just as in the pulp and paper mill, the exergy value of the unutilized flows will be significantly lower than the energy value. It may also be noted that efficiency at the steel plant and rolling mill in question has been improved by the replacement of two furnaces with one, built for a higher capacity. Technology ought to be developed to prevent heat losses between casting and rolling.

In conclusion, it should als be mentioned that the application of the exergy concept provides information for long-term planning of resource management. Today, there is competence and experience for short-term planning. Unfortunately, this is not the case for longer-term planning. This often obstructs development of new efficient technology. The concept of exergy is thus a worthwhile complement to present-day planning instruments.

Acknowledgement - This work was supported by an Operating Grant from the National Swedish Board for Technical Development, for which support I am most grateful.

\section{REFERENCES}

1. G. Wall, Report no. 83-11, Physical Resource Theory Group, Chalmers Univ. of Techn., S-412 96 Göteborg, Sweden (1983).

2. N. L. S. Carnot, Réflections sur la puisance motrice du feu et sur les machines propres a développer cette puissance, Bachelier, Paris (1824); Fox, R. (ed.), Libraire Philosophique J. Vrin, Paris (1978).

3. J. W. Gibbs, Collected Works, Yale University Press, New Haven (1948). Originally published in Trans. Conn. Acad., Vol. II, pp. 382-404 (1873).

4. Z. Rant, Forschung Ing.-Wesens 22, 36 (1956).

5. H. D. Baehr, Energie und Exergie, VDI-Verlag, Düsseldorf (1965).

6. R. B. Evans, "A proof that essergy is the only consistent measure of potential work", Thesis, Dartmouth College, Hanover, New Hampshire (1969).

7. G. Wall, "Exergy - a useful concept within resource accounting", Report no. 77-42, Physical Resource Theory Group, Chalmers Univ. of Techn., S-412 96 Göteborg, Sweden (1977).

8. R. C. Weast, Handbook of Chemistry and Physics, 63rd ed., CRC Press, Cleveland, Ohio (1982-83).

9. J. Szargut, Energy 5, 709 (1980).

10. G. Wall ed., Proc. Conf. Energy Quality Concepts (partly in Swedish), Physical Resource Theory Group, Chalmers Univ. of Techn., S-412 96 Göteborg, Sweden (1981).

11. E. P. Gyftopoulos, L. Lazaridis and T. Widmer, Potential fuel effectiveness in industry, Ballinger, Cambridge, Mass. (1974).

12. B. A. Hedman, H. L. Brown and B. B. Hamel, Energy 5, 931 (1980).

13. J. Fors and B. Nord, Report no. 209-1981, National Swedish Board for Technical Development, Stockholm (1980).

14. G. Wall, Energy 11, 957 (1986).

15. J. Fors and R. Hardell, Report no. 88-1978 (in Swedish), National Swedish Board for Technical Development, Stockholm (1978). 